\title{
LIFE EVENTS WITH STRESSFUL EFFECT ON PATIENTS WITH SCHIZOPHRENIA ACCORDING TO THE SEX AND AGE
}

\author{
Rinaldo Shishkov ${ }^{1}$, Mila Georgieva ${ }^{2}$, Lilia Nikolova ${ }^{1}$ \\ 1) Department Psychiatry and Medical Psychology, \\ 2) Department Economics and management of healthcare, \\ Medical University - Varna, Bulgaria,
}

\begin{abstract}
According to the literature life events with stressful effect are significant both for initiation and progress of the schizophrenia. Having this in mind we set our aim to be investigating the relationship between life events (considered as stressful), sex and age trough questioning 50 patients with paranoid schizophrenia. The results of our study showed presence of correlation between some of the studied life events, assessed as stressful. The analysis of the data revealed that both sex and age are influencing the assessment of the significance of the life events and "increases" their importance both for women and men.
\end{abstract}

Key words: schizophrenia, stressful events.

\section{INTRODUCTION}

People with schizophrenia are subject of many adverse effects from the social environment, which upset their social adaptation (9). This is a prerequisite ,for a life in a chronic stress" with the all following consequences, mostly related to the progress of the schizophrenia, development of concomitant diseases and higher mortality rate (16).

There are studies that indicate that people with schizophrenia are more vulnerable from the impact of the social stress in comparison with mentally healthy people. (8). These studies correlate with others similar to them and thus show the relation between stressful factors and the severity of the clinical manifestation of the disease (4). From the other side there are opinions that because of the disease and the related with it "perception of the world" these patients are distant from the social failures and respectively they don't show the expected ,poor” quality of life (9).

The psychosocial stress/ distress events are regarded as an important component influencing the biological answer of the organism. It has been proven that the negative effect of the stress is stronger in "chronic" than in "acute" mode (12). It has been found that the abnormally activated (especially from chronic stress) hipotalamo-hypophysisadrenal axis causes neurotoxicity in the CNS (central nervous system).

This effect is related to the increased level of the glucocorticoid hormones (4). The fore coming conclusion is an exceptionally strong argument for formulation of the relation "schizophrenia - stress/ distress" and its action as a pathogenetic mechanism of the disease. At this base is structured the hypothesis for the stress model of the schizophrenia, ,that puts in the foundation of the initiation and relapses of the disease the stressful events of the social environment $(8,15)$. With stress/ distress effect are related many processes in the CNS as disturbed neuronal plasticity, disorder in the activity of the microglia and so on $(4,7,10,11)$

\section{AIM OF THE STUDY}

Giving the literature findings we set an aim to study the relation between ,stressful life events”, the age, the sex and the continuance of the disease.

\section{MATERIAL AND METHODS}

Following the aim of our study we investigated 50 patients with paranoid schizophrenia (diagnosis F20, ICD 10) - 21 of them were men and 29 women in the age range 18-60 years. The continuance of the disease (for both sexes) is between 1 and 20 years.

For studying of the life events with stressful effect in Bulgarian population in the present socio-economic reality the investigation was performed trough "open interview". The participating patients were invited to point important to them life events, which they consider as stressful and to point out their "severity".

Later the life events were unified in groups according to their content - "Parting with a close person"; "Death of a close relative (mother, grandmother, grandfather, husband, child)", "Conflicts at home and with surrounding people", "Life without home", "Every day but not very significant troubles"; „Lack of finances“; "Job loss”; "Strongly severe and significant troubles“; „Life without friends or relatives (alone)". It was statistically studied the influence of the factors "sex" and ,age" in the assessment of the life events 
as stressful. The statistical processing was conducted by methods for dispersion analysis (one-way and two-way ANOVA) and correlation analysis.

\section{RESULTS AND DISCUSSION}

It was studied the influence of the factor ,sex” on the assessment of the life events as significant and stressful, as if on the assessment of their severity. The results of the group patient "Women" are presented on table 1, and of the group „Men“- on table 2. The used statistical method is dispersion analysis (two-way ANOVA):

Table 1. Influence of the factor „sex” on the assessment of the life events as significant, stressful and the judgment of their severity (group „Women”)

\begin{tabular}{|l|c|c|c|c|}
\hline Source of Variation & \% of total variation & P value & & \\
\hline Column Factor & 19,14 & $<0.0001$ & & \\
\hline Row Factor & 11,05 & 0,0973 & & \\
\hline Source of Variation & P value summary & Significant? & & \\
\hline Column Factor & $* * *$ & Yes & & F \\
\hline Source of Variation & Df & Sum-of-squares & Meansquare & 6,581 \\
\hline Column Factor & 9 & 81,24 & 9,027 & 1,425 \\
\hline Row Factor & 24 & 46,91 & 1,955 & \\
\hline Residual & 216 & 296,3 & 1,372 & \\
\hline
\end{tabular}

The analysis of the results shows presence of statistically significant influence of the sex of the patients with schizophrenia on their assessment of the investigated life events. Very similar are the results in studying influence of the factor "sex" on the assessment of the life events from men with schizophrenia (Table 2):

Table 2. Influence of the factor „sex" on the assessment of the life events as significant, stressful and the judgment of their severity (group „Men”)

\begin{tabular}{|l|c|c|c|c|}
\hline Source of Variation & \% of total variation & P value & & \\
\hline Column Factor & 14,39 & 0,0013 & & \\
\hline Row Factor & 6,09 & 0,9465 & & \\
\hline Source of Variation & P value summary & Significant? & & \\
\hline Column Factor & $* *$ & Yes & & F \\
\hline Source of Variation & Df & Sum-of-squares & Meansquare & 3,620 \\
\hline Column Factor & 7 & 21,49 & 3,071 & 0,5365 \\
\hline Row Factor & 20 & 9,101 & 0,4551 & \\
\hline Residual & 140 & 118,8 & 0,8483 & \\
\hline
\end{tabular}

In result of the conducted interview and the study of the influence of the factor "sex" on the defining and assessment of the stressful life events and their severity scale we concluded that this factor has a statistically significant influence both on women and men.

The results of the investigation of the influence of 
the factor "age" on the perception and assessment of the studied life events was conducted separately for each sex. On table 3 are presented the results from the group "Men" and on table 4 - from the group "Women". For data processing was used dispersion analysis according to the age of the patients.

Table 3. Influence of the factor "Age" on the perception and assessment of the life events (group „Men”)

\begin{tabular}{|l|l|}
\hline Degrees of freedom & $\mathrm{f}_{1}=3, \mathrm{f}_{2}=61$ \\
\hline between-group variance & 3081,333 \\
\hline intragroup variance & 6,07541 \\
\hline F emp. & $507,1811477 \mathbf{P}=\mathbf{0 , 0 1}$ \\
\hline
\end{tabular}

We accepted the alternative hypothesis $\left(\mathrm{H}_{1}\right)$, i.e. there is a statistically significant difference in the severity scale, pointed out by the male patients according to their age.

Table 4. Influence of the factor "Age" on the perception and assessment of the life events (group „Men”)

\begin{tabular}{|l|l|}
\hline Degrees of freedom & $\mathrm{f}_{1}=4, \mathrm{f}_{2}=78$ \\
\hline between-group variance & 23144,16 \\
\hline intragroup variance & 5,507692 \\
\hline F emp. & $4202,152 \mathbf{P}=\mathbf{0 , 0 5}$ \\
\hline
\end{tabular}

We accepted the alternative hypothesis $\left(\mathrm{H}_{1}\right)$, i.e. there is a statistically significant difference in the severity scale, pointed out by the female patients according to their age.

\section{CONCLUSION:}

Based on the literature review about the role of the distress on the initiation and progress of the schizophrenia (9) and the results from our study could be concluded that patients with schizophrenia assess the significance of life events in different way depending on their sex. During the investigation we found out that male patients show less emotional commitment to "the significant social problems" than female patients. Regardless of the way of perception of the studied life events, the age is a factor that makes the stress effect stronger for the "negative events" both for women and men (but more notable in the group of female patients).

Despite these differences as a whole the studied patients didn't manifest "poor" quality of life. A possible explanation of this fact is the weak emotional commitment to stressful/ distressful events for both for men and women (but more strongly notable among men) (1). This could be related as well with the nature of the disease. In this respect similar conclusion is made by Norman et al. (1993), who found that the patients with schizophrenia are not exposed to a stronger stressful effect of the social environment than the overall population (9). Referring on the fact that schizophrenic patients have disturbed "basic levels" and diurnal rhythm of the corticosteroids (15), the role of the distress (even if it is not very manifested) could lead to organic brain changes, that are typical for "significant" and chronic stress/ distress.

The presented data and the described in the literature role of the stress, causing higher basic level and disrupted diurnal rhythm of the glucocorticoid hormones are both throwing a bridge between the psychological and the biological, i.e. the perception of stress/ distress and the disturbed neuronal function in the brain zones are strongly associated with the schizophrenic symptoms $(4,7$, and 10$)$.

\section{REFERENCES:}

1.Hristova M, Boncheva I. Life events and specifics of the experiences in patients with hypothalamic metabolic syndrome. Endocrinology, 2006, 11(1):42-46 (in Bulgarian)

2. Allebeck P, Rodvall Y, Wistedt B. Incidence of rheumatoid arthritis among patients with schizophrenia, affective psychosis and neurosis. Acta Psychiatr Scand. 1985 Jun;71(6):615619. [PubMed]

3. Bonchewa Iv. Positive Psychotherapy as a support of psychotic patients after acute status. 3rd International Conference on positive
Psychoterapy, Varna, 2003 Abstracts, p.14.

4. Cotter D, Pariante CM. Stress and the Progression of the Developmental Hypothesis of Schizophrenia. $\mathrm{Br} J$ Psychiatry. 2002 Nov;181:363-365. [PubMed] [CrossRef]

5. Fung SJ, Joshi D, Allen KM, Sivagnanasundaram S, Rothmond DA, et al. (2011) Developmental Patterns of Doublecortin Expression and White Matter Neuron Density in the Postnatal Primate Prefrontal Cortex and Schizophrenia. PLoS ONE 6(9): e25194. [CrossRef]
6. Kirkbride JB, Barker D, Cowden F, Stamps R, Yang M, Jones PB, et al. Psychoses, ethnicity and socioeconomic status. Br J Psychiatry. 2008 Jul;193(1):18-24. [PubMed] [CrossRef]

7. Lawrie SM, Whalley H, Byrne M, et al. (2000) Brain structure change and psychopathology in subjects at high risk of schizophrenia. Schizophrenia Research. 41, p.11

8. Neuchterlein KH, Dawson ME. A heuristic vulnerability/ stress model of schizophrenic episodes. Schizophr Bull. 1984, 10(2):300-312. [PubMed]

9. Norman RM, Malla AK. Stressful 
life events and schizophrenia. A review of the research. Br J Psychiatry. 1993 Feb;162:161-166. [PubMed]

10. Pantellis C, Velakoulis D, Suckling J, et al. (2000) Left medial temporal lobe volume reduction occurs during the transition from high risk to first episode psychosis. Schizophrenia Research, 41, 35.

11. Jope RS, Roh MS. Glycogen Synthase Kinase-3 (GSK3) in Psychiatric Diseases and Therapeutic Interventions. Curr Drug Targets. 2006
Nov;7(11): 1421-1434. [PubMed]

12. Selye, H. (1974). Stress without distress. Philadelphia: J. B. Lippincott Co.

13. Toro CT, Deakin JF. Adult neurogenesis and schizophrenia: A window on abnormal early brain development? Schizophrenia Research. 2007 Feb;90(1-3):1-14. [PubMed] [CrossRef]

14. van Zelst C. Stigmatization as an Environmental Risk in Schizophrenia: A User Perspective. Schizophr Bull. 2009
Mar;35(2):293-296.

[PubMed]

[CrossRef]

15. Walker EF, Diforio D. Schizophrenia a neural diathesis-stress model. Psychol Rev. 1997 Oct;104(4):667-685. [PubMed] [CrossRef]

16. Xu B, Roos JL, Dexheimer P, Boone B, Plummer B, Levy S, et al. Exome sequencing supports a de novo mutational paradigm for schizophrenia. Nature Genetics. 2011 Aug 7; 43(9):864-868. [PubMed] [CrossRef]

\section{Corresponding author:}

Rinaldo Shishkov, MD, PhD

Department "Psychiatry and medical psychology", Medical University of Varna, 1, Hr. Smirnenski Boul., 9010 Varna, Bulgaria E-mail: rshishkov@abv.bg 